\title{
Endogenous Ouabain Changes Rapidly During Cardiac Pulmonary by Pass
}

Elena Bignami², Nunzia Casamassima' ${ }^{1}$, Elena Frati ${ }^{2}$, Elisabetta Messaggio', Laura Corno ${ }^{2}$, Alberto Zangrillo² and Paolo Manunta ${ }^{1 *}$

${ }^{1}$ Nephrology and Dialysis Unit, San Raffaele Scientific Institute, Università Vita Salute San Raffaele, Milan, Italy

${ }^{2}$ Anesthesia and Intensive Care Unit, San Raffaele Scientific Institute, Università Vita Salute San Raffaele, Milan, Italy

\begin{abstract}
Objective: Endogenous Ouabain (EO) is a cardiac glycoside secreted from the adrenal glands that plays a role sodium homeostasis with hemodynamic and renal effects. It is considered a stress hormone. The role of EO during critical illness is unknown.
\end{abstract}

Aim: to study 1. the time course of EO during cardio pulmonary bypass (CPB) and 2. the ability of renal replacement therapy (RRT) to remove EO.

Methods: in 11 patients undergoing mitral valve repair were performed an intraoperative time course with serial blood samples for EO, serum creatinine, NT-proBNP and cathecolamines. During surgery blood samples were repeated every 15 minutes. Then all these biomarkers were dosed at the end of surgery, 4 hours and 24 hours later. In the 15 patients undergoing EO time course during RRT, EO plasma levels were measured when AKI (Acute Kidney Injury) occurred (at R of RIFLE and 24 hours after this moment).

Results: In patients undergoing mitral valve repair EO levels increased 15 minutes after the beginning of CPB reaching the peak 4 hours after surgery (from $198 \pm 10$ to $350 \pm 130 \mathrm{pmol} / \mathrm{L}, \mathrm{p}<0.0001$ ). Circulating catecholamine (Norepneephrine ad Epinephrine) levels increased immediately after CBP. NT-proBNP increased only 4 hours after surgery, reaching high plasma levels when EO decreased. Plasma EO and creatinine levels resulted significantly directly related $(r=0.45, p=0.01)$ after surgery. Continuous RRT did not modified circulating EO in AKI patients.

Conclusion: EO may be considered a stress hormone that changes rapidly during acute volume expansion and blood pressure fall during CPB.

Keywords: Na pump inhibitor; Cardiac surgery; Cardiac glycosides; Adrenal gland; Hormone

Abbreviations: ACTH: Adreno Cortico Tropic Hormone; ANG II: Angiotenisin II; AKI: Acute Kidney Injury; CPB: Cardio Pulmonary Bypass; CYP11A1: Cholesterol side-chain cleavage; EO: Endogenous Ouabain; EuroSCORE : European System for Cardiac Operative Risk Evaluation; HSD3B: 3 $\beta$-hydroxysteroid dehydrogenase; NTproBNP: N-terminal pro-brain-type natriuretic peptide; RRT: Renal Replacement Therapy; SNP: Single Nuucleotide Polymorphism

\section{Introduction}

Acute kidney injury (AKI) is now recognized as a major public health problem affecting millions of patients worldwide and leading to decreased survival or increased progression of underlying chronic kidney disease, and, sometimes, to new onset of chronic kidney disease [1]. Furthermore, AKI is not a single disease but rather a syndrome comprising multiple clinical conditions. Outcomes in AKI are influenced by the underlying disease causing the condition, as well as by the severity and duration of renal impairment and by the baseline condition of the patient [2]. AKI occurs in as many as $40 \%$ of patients after cardiac surgery and requires dialysis in $1 \%$ of cases $[3,4]$. AKI is associated with an increased risk of mortality and morbidity, predisposes patients to a longer hospitalization, requires additional treatments, and increases the hospital costs. In 2005, Chertow and colleagues [5] demonstrated that small changes in serum creatinine, like a rise in serum creatinine by $0.3 \mathrm{mg} / \mathrm{dl}$, were indicative of significant renal dysfunction. They also find an association between high in hospital serum creatinine levels and mortality. Although serum creatinine is typically used for diagnosis of $\mathrm{AKI}$, it is an insensitive and unreliable biomarker during acute changes of renal function. In fact serum creatinine does not increase until about half of the kidney function is lost [6]. For this reason there is need for new early biomarkers for AKI. New biomarkers are likely to be useful in facilitating early diagnosis, guiding targeted interventions and monitoring disease progression.

Endogenous Ouabain (EO) is an adrenal stress hormone with potential hemodynamic and renal effects, secreted by adrenal gland [7]. EO is a cardiac glycoside, structurally similar to digoxin, that modulates the activity of membrane bound $\mathrm{Na}^{+} / \mathrm{K}^{+}$-ATPase pump and induces signal transduction via a second messenger system [8]. A growing number of clinical and experimental evidences identified high concentrations of this hormone in human and animal adrenal glands, which are proposed to be a primary source of EO in mammals $[8,9]$. Furthermore, EO modulates $\mathrm{Na}^{+} / \mathrm{K}^{+}$-ATPase in the vascular bed decreases vascular compliance by increasing smooth muscle tone $[7,10]$ and this effect is ouabain specific [11]. In the heart, EO activated though $\mathrm{Na}^{+} / \mathrm{K}^{+}$-ATPase generated Src-kinase second messenger pathway promotes cardiomyocyte hypertrophy [12]. Observational data in naïve hypertensive patients revealed that elevated EO concentrations are associated with increased diastolic blood pressure and left ventricular hypertrophy [13]. Prolonged ouabain infusion in rats causes an increase in plasma creatinine, blood pressure and tubular $\mathrm{Na}$ reabsorption.

*Corresponding author: Paolo Manunta, MD, Chair of Nephrology, San Raffaele Scientific Institute, Università Vita Salute San Raffaele, Via Olgettina 60, 20132 Milan, Italy, Tel: ++39 02 26433890/5330; Fax: ++39 02 26432384; E-mail: manunta.paolo@hsr.it

Received November 02, 2011; Accepted December 24, 2011; Published December 27, 2011

Citation: Bignami E, Casamassima N, Frati E, Messaggio E, Corno L, et al. (2011) Endogenous Ouabain Changes Rapidly During Cardiac Pulmonary by Pass. J Steroids Hormon Sci S3:002. doi:10.4172/2157-7536.S3-002

Copyright: ( 2011 Bignami E, et al. This is an open-access article distributed under the terms of the Creative Commons Attribution License, which permits unrestricted use, distribution, and reproduction in any medium, provided the original author and source are credited. 
[7], Recently [14], we have shown the relationship between EO and impaired glomerular filtration rate as direct consequence of long exposure to increased level of plasma EO in hypertensives. Therefore, we conducted these prospective observational studies to test the time course of circulating EO changes during cardio pulmonary bypass $(\mathrm{CPB})$, where acute volume and blood pressure modification occurs. We also test whether post-operative AKI may influence by EO and we verify the ability of renal replacement therapy (RRT) to clear EO.

\section{Materials and Methods}

In the setting of cardiac surgery, after Ethical Committee approval and patients' written consent, were enrolled in the study 11 consecutive patients undergoing mitral valve repair and 15 consecutive patients undergoing postoperative AKI threaded with RRT.

For the 11 patients undergoing mitral valve repair inclusion criteria were: age between 18 and 75 years old, mitral valve repair, pre-operative ejection fraction $>60 \%$ and pre-operative end-diastolic diameter $<60$ $\mathrm{mm}$. Exclusion criteria were no written consent, other than mitral valve repair in median sternotomy, any preoperative comorbidity and perioperative need for inotrops or vasoconstrictors. Disease severity was scored according to European System for Cardiac Operative Risk Evaluation (EuroSCORE) [15].

For the 15 patients treated with continuous renal replacement therapy (CRRT) the inclusion criteria were: age $>18$ years old, cardiac surgical intervention and AKI treated with CRRT. The exclusion criteria were no written consent and other type of surgery (ex vascular surgery).

All patients underwent preoperative clinical evaluation, routine blood tests and instrumental examinations (resting ECG, echocardiography).

All patients received a standardized anesthetic management. Premedication (morphine $0.1 \mathrm{mg} / \mathrm{kg}$ intramuscularly; scopolamine $0.003 \mathrm{mg} / \mathrm{kg}$ intramuscularly) was administered 1 hour before surgery; general anesthesia was induced with fentanyl $(10-20 \mathrm{mcg} /$ $\mathrm{kg}$ ) and propofol ( 2 to $4 \mathrm{mg} / \mathrm{kg}$ ). To facilitate endotracheal intubation, rocuronium $0.5 \mathrm{mg} / \mathrm{kg}$ was administered. Anesthesia was maintained with propofol ( 2 to $4 \mathrm{mg} / \mathrm{kg} / \mathrm{h}$ ), or sevofluorane (end-tidal concentration $>1 \mathrm{MAC}$ ) and additional doses of fentanyl when required. All operations were performed by one of six surgeons. All patients underwent median sternotomy. The surgery is performed through the cardiopulmonary bypass ( $\mathrm{CPB}$ ), a heart-lung machine that replaces the function of these organs. The heart must be cold, empty and still. The heart is stopped with a cardioplegic solution.

Standard CPB technique was used as previously reported [16]. According to the needs of the patients were infused fluids administered diuretics and inotrops, respectively to maintain urinary output above $1 \mathrm{ml} / \mathrm{kg} / \mathrm{he}$ and to ensure a mean arterial pressure of $70 \mathrm{mmHg}$.

After surgery, all patients were transferred to intensive care unit and therated according to standardized protocols. In all patients postoperative renal function was monitored with serum creatinine and urinary output and AKI was assessed using the RIFLE classification [17]. When AKI occurred, the first treatment was hemodynamic optimization with fluid challenge and inotrops to rise a Mean Blood Pressure $>70 \mathrm{mmHg}$ and a urinary output $\geq 1 \mathrm{ml} / \mathrm{kg} / \mathrm{h}$.

\section{Renal Replacement Therapy}

In our institution, continuous renal replacement therapy (RRT) is the preferred option in acutely ill patients and the only initial treatment option. For the purpose of this study, indications for RRT were: worsening of renal function despite hemodynamic optimization, refractory fluid overload, hyperkalemia (plasma potassium concentration $>6.5 \mathrm{meq} / \mathrm{L}$ ) or rapidly rising potassium levels and metabolic acidosis $(\mathrm{pH}$ less than 7.1) refractory to medical therapy.

All patients signed informed consent before surgery and preoperative blood sample for $\mathrm{EO}$ were drawn. In the 11 patients undergoing mitral valve repair were performed an intraoperative time course with serial blood samples for EO, serum creatinine, NTproBNP and cathecolamines (epinephrine and norepinephrine) During surgery blood samples were repeated every 15 minutes. Than all these biomarkers were dosed at the end of surgery, 4 hours and 24 hours later. In the 15 patient undergoing EO time course during RRT, EO plasma levels were measured when AKI occurred (at R of RIFLE and 24 hours after this moment), at the beginning of CRRT and during the treatment (1 hours, 3 hours, 6 hours, 12 hours, 24 hours, 36 hours, 48 hours). During RRT EO was dosed also in dyalisate .In all patients were monitored vital signs and renal function (serum creatinine, GFR and urinary output).

\section{Statistical Analysis}

Descriptive statistics are presented with mean and SD or median as appropriate, ordinal data are presented with number and percentage. Comparisons of nominal data were by means of the chisquare test or Fisher's exact test where indicated.

\section{Results}

\section{EO Time Course During Mitral Valve Repair}

The 11 patients, undergoing EO time course during mitral valve repair, were $45 \pm 3.5$ years old (Table 1 ). In patients undergoing mitral valve repair EO levels increased 15 minutes after the beginning of CPB reaching the peak 4 hours after surgery (from $198 \pm 10$ to $350 \pm 130 \mathrm{pmol} / \mathrm{L}, \mathrm{p}<0.0001$, Figure $1 \mathrm{~A}$ panel), while serum creatinine remained unmodified (Figure 1, C panel). Plasmatic sodium levels (not shown) and haematocrit decreased (-35\% Figure $1 \mathrm{~B}$ panel) during $\mathrm{CPB}$, simultaneously with the acute circulating volume expansion. Circulating catecholamine (Norepneephrine ad Epinephrine) levels increased immediately after CBP (Figure 2, B and C panel respectively). NT-proBNP increased only 4 hours after surgery (Figure 2, E panel), reaching high plama levels when EO decreased.

\section{EO and Plasma Creatinine}

In thirty-one the plasma creatinine 48 hours after cardiac surgery reached plateau values (Figure 3, A panel). However plasma EO showed a top increase after 24 hours and started to decrease in $2^{\text {nd }}$ day after surgery (Figure 3, B panel). Furthermore, plasma EO and creatinine levels resulted significantly directly correlate $(\mathrm{r}=0.45, \mathrm{p}=0.01)$ after surgery.

\section{EO Time Course During RRT} 2.

The most important preoperative characteristics are shown in Table

EO levels remained high from the preoperative sample to all the treatment with continuous RRT (Figure $4 \mathrm{~A}$ panel). We also dosed EO in the dyalisate, but it was not detectable. These findings suggest that EO has no dialytic clearance during RRT. Also hematocrit levels (Figure $4 \mathrm{~B}$ panel), after a decrease in the first postoperative hours explainable with intraoperative blood loss, remained unchanged. Mean serum 


\begin{tabular}{|l|l|l|}
\hline & Mean/Median/Percentage & SD/IQ range \\
\hline Age (years) & 74 & 6.5 \\
\hline Female (N; \%) & $7 ; 46 \%$ & - \\
\hline EuroScore (\%) & 15 & $(10.3-20.9)$ \\
\hline Previous cardiac surgery (N; \%) & $7 ; 46 \%$ & - \\
\hline Other than isolated CABG (N;\%) & $11 ; 73 \%$ & - \\
\hline NYHA 3 and 4 (N;\%) & $10 ; 66 \%$ & - \\
\hline Ejection Fraction $(\%)$ & 50.5 & 12.3 \\
\hline End diastolic diameter (mm) & 55.2 & 8.2 \\
\hline Hypertension (N;\%) & $8 ; 53 \%$ & - \\
\hline Cronic Renal Failure (N;\%) & $8 ; 53 \%$ & - \\
\hline Diabetes Mellitus (N;\%) & $4 ; 26 \%$ & - \\
\hline Serum creatinine (mg/dL) & 1.32 & 0.59 \\
\hline EO (pmol/L) & 281 & $(181.7-482.3)$ \\
\hline
\end{tabular}

Table :1 Preoperative caracteristics.

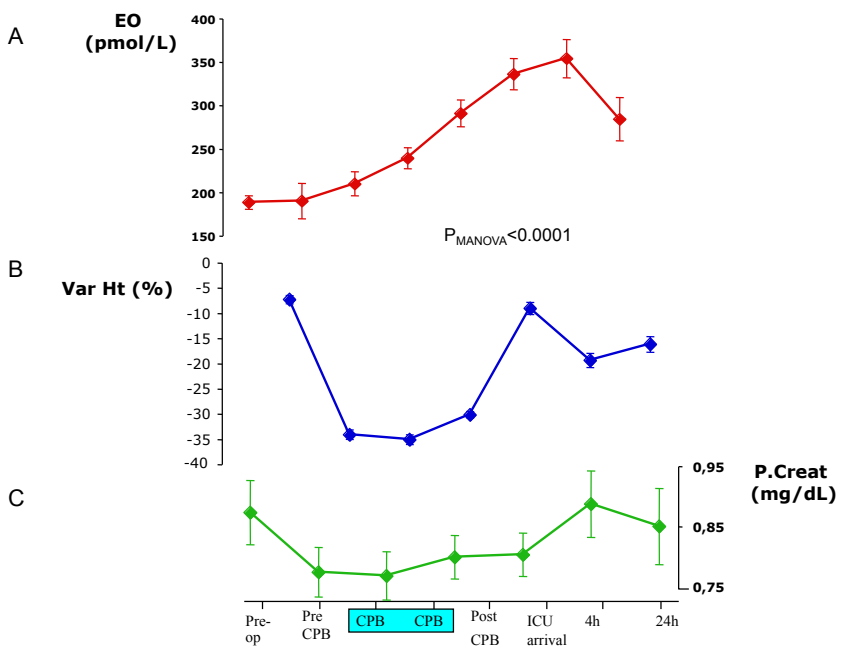

Figure 1: EO time course during CPB. Panel A: 15 min after general anesthesia was induced plasma EO (red) start to rise achiving the maximum increase 4 hour after CBP. (MANOVA repeated measure $p<0,0001$ after correction for SEX, AGE, BMI, Euroscore). Panel B: the haematocrit (bleu) expressed as variation percent (Var $\mathrm{Ht}(\%))$, decrease $35 \%$ from baseline suggesting an acute volume espansione before CEC. Panel C: plasma creatinine (green) durino volume expansion decresed as consequece of plasma diulution.

creatinine (Figure $4 \mathrm{C}$ panel) rise progressively until it reaches a peak at the start of RRT, then gradually decrease due to dialysis clearance of serum creatinine. The mean arterial pressure (Figure $4 \mathrm{D}$ panel) reaches the minimum average of 24 hours after R of RIFLE, then fluctuated between $73 \mathrm{mmHg}$ and $80 \mathrm{mmHg}$ of mean value during the dialysis treatment continuously.

\section{Discussion}

The most striking observation in this study is the marked and rapid change of circulating plasma EO after induction of anesthesia. Neither catecholamines nor NT-proBNP can be a stimulus for EO release, because their increase is delayed compared to that of EO (Figure 1). EO rapid increase could be induced by acute volume expansion due to cardioplegia and blood pressure fall, after general anesthesia induction and during $\mathrm{CPB}$ [18]. AKI in cardiac surgery is mainly related to the adverse effects of $\mathrm{CPB}$ and cardioplegia, which causes dramatic hemodynamic changes, including marked volume expansion and change from pulsatile to continuous flow. $\mathrm{CPB}$ and cardioplegia are necessary for cardiac surgery, because they make possible to work on a cold, empty and still heart. A long series of experimental and clinical data supports the notion that endogenous glycoside is secreted in the circulation in response to volume expansion $[7,19,20]$.

Endogenous Ouabain may be considered a stress hormone secreted by adrenals glands as supported by:

I. In an early study in patients with primary aldosteronism, EO levels in mixed inferior vena cava blood were more than fivefold higher than in normal controls [21]. We suggested recently that a step up in adrenal venous plasma of about threefold was likely in that study [22]. Further studies using methods based on mass spectrometry are needed to confirm this impression and to provide crucial proof of the appropriate venous gradients in humans. In work with conscious, afebrile dogs with surgically placed adrenal venous catheters, the EO content of the adrenal venous effluent was about fivefold to sixfold higher than that of arterial blood [23].

II. Elevated plasma levels of EO were found in two rare hypertensive patients with nonclassic adrenocortical tumors [24]. Removal of the tumors was associated with a normalization of plasma EO levels and the remission of hypertension. The results were compatible with those in other patients with aldosteronesecreting tumors [25], which also hyper secrete EO and cause hypertension.

III.Cultured human and bovine adrenocortical cells secrete EO into the culture fluid [26]. The secretion is augmented by angiotensin II, adrenocorticotropic hormone (ACTH), and possibly vasopressin, as well as $\alpha_{1}$ adrenoceptor agonists $[22,26]$. With contemporary dietary $\mathrm{Na}^{+}$intakes and with plasma renin activity largely suppressed, both plasma $\mathrm{K}^{+}$and ACTH appear to be key regulators of circulating $\mathrm{EO}$ in humans $[27,28]$. The adrenal biosynthesis of EO involves cholesterol side-chain cleavage (CYP11A1) and $3 \beta$-hydroxysteroid dehydrogenase (HSD3B) with sequential metabolism of pregnenolone and progesterone $[29,30]$.

IV. The renal excretion of cardiac glycosides is mediated in part by the organic anion transporter (SLCO4C1) at the basolateral membrane [31] and in part by the Pglycoprotein (PGP, encoded by MDR1) [32] at the apical membrane of the nephron. Accordingly, a single nucleotide polymorphism (SNP) and haplotype-based association study was performed with a total of 26 informative SNPs in a large cohort of hypertensive patients. In that study, CYP11A1 and MDR1 loci were associated with circulating EO and diastolic BP, likely reflecting their influence on EO synthesis and transmembrane transport, respectively [33].

$\mathrm{V}$. The acute increase of EO has been previosly report under stress condition. Bauer et al. [34] have shown that the marked and rapid change of plasma EO in humans and dogs during physical exercise. Moreover, in dogs the increase in EO release is completely abolished by $\beta$-blockade and ACE inhibition suggesting that both $\beta_{1}$-adrenergic stimulation and the reninangiotensin system are immediately involved in EO release during exercise. Furthermore, an increase in plasma ANG II causes neuronal activation in hypothalamic nuclei and a pressor response, presumably by increasing sympathetic drive. Leenen et al. [35] postulated that the activation of a neuromodulatory pathway, involving aldosterone and "ouabain," is involved in these responses. 
A

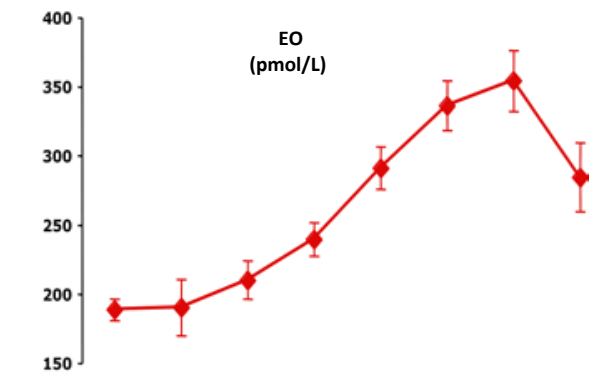

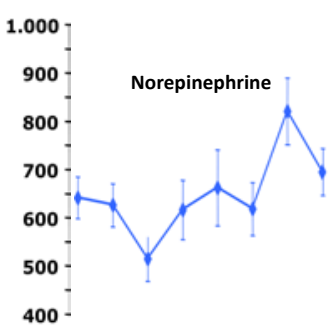
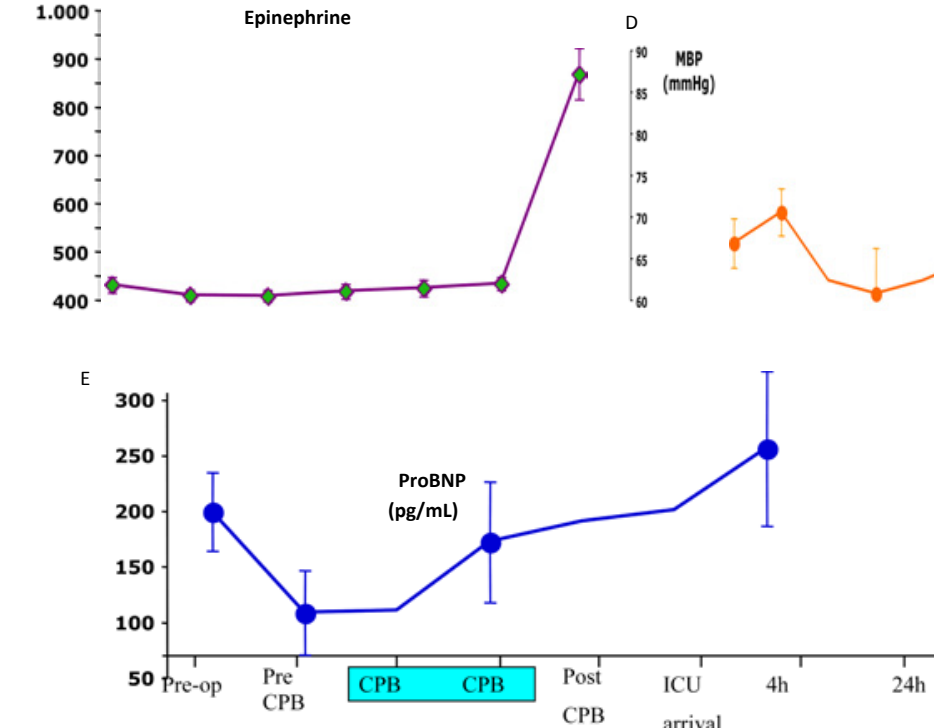

Figure 2: Norepinefrine (orange, B panel), epinephrine (bleu, C panel) and ProBNP (green, E panel) as expected a late rise was observed when EO decreased However a significant fall in blood pressure (bluette, D panel) during CPB was present.

A

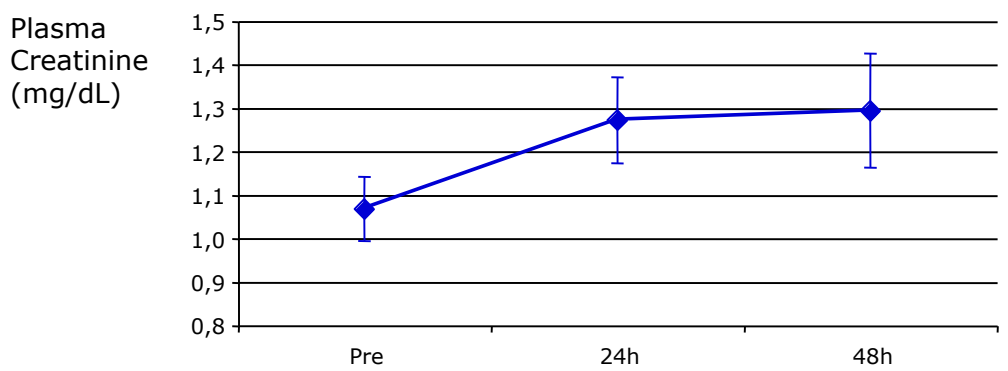

$\mathrm{B}$

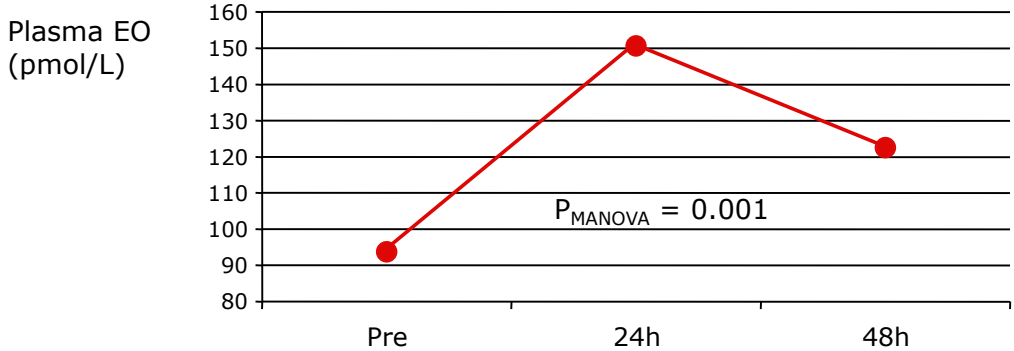

Figure 3: Plasma creatinine (A panel) and Endogenous Ouabain (B panel) 24 and 48 hours after CPB. 
Citation: Bignami E, Casamassima N, Frati E, Messaggio E, Corno L, et al. (2011) Endogenous Ouabain Changes Rapidly During Cardiac Pulmonary by Pass. J Steroids Hormon Sci S3:002. doi:10.4172/2157-7536.S3-002
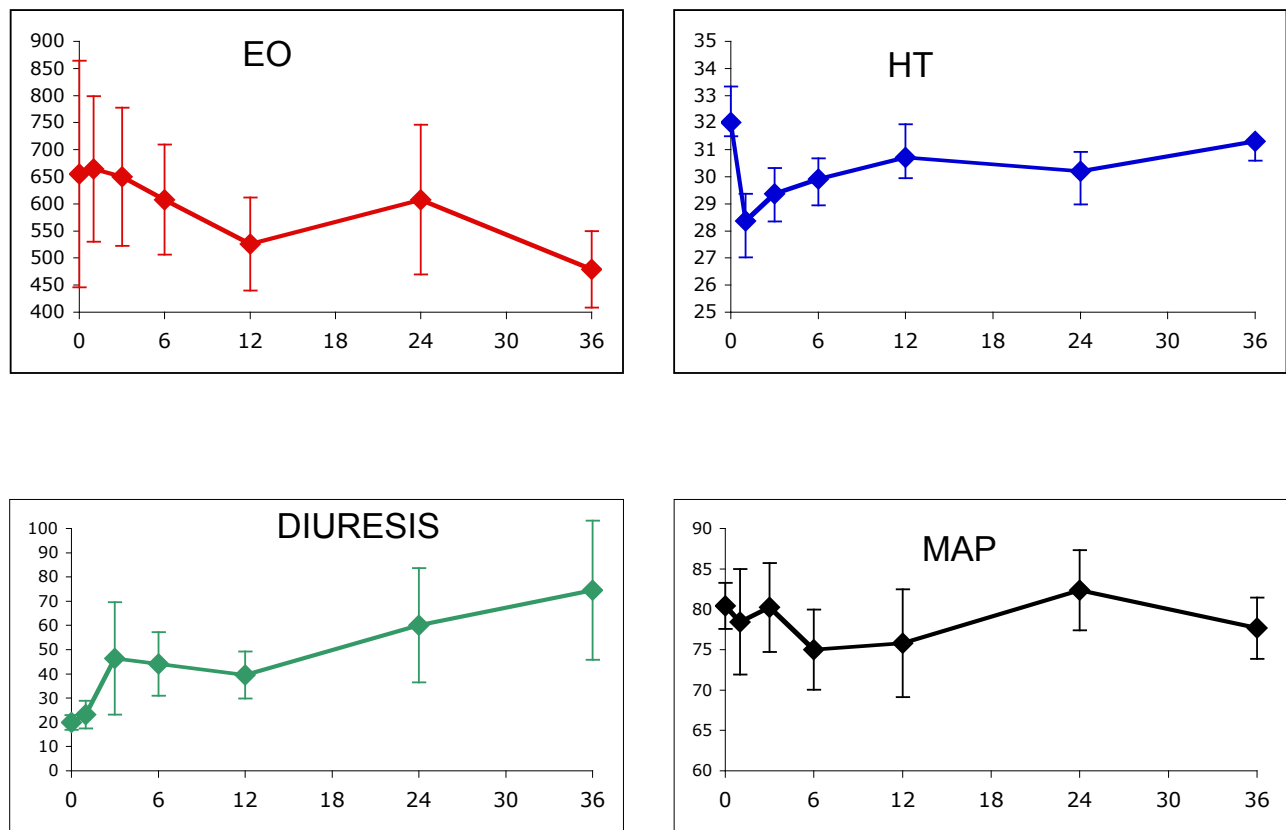

Figure 4: RRT. During renal replacement therapy EO did not changes significantly as well as hematocrit (HT), mean arterial pressure (MAP). However, urinary out-put increase as effect of continous RRT

\begin{tabular}{|l|l|l|}
\hline & Mean/Median/Percentage \\
\hline R of RIFLE serum creatinine $(\mathrm{mg} / \mathrm{dl})$ & 2.47 \\
\hline R of RIFLE EO levels $(\mathrm{pmol} / \mathrm{L})$ & 354 \\
\hline Serum creatinine at RRT start $(\mathrm{mg} / \mathrm{dl})$ & 3.40 \\
\hline EO levels at CRRT start $(\mathrm{pmol} / \mathrm{L})$ & 473 \\
\hline Length of RRT (hours) & 114 \\
\hline Predilution $(\mathrm{N} ; \%)$ & $8 ; 53 \%$ & $(331-579)$ \\
\hline Postdilution $(\mathrm{N} ; \%)$ & $7 ; 47 \%$ & $\mathbf{( 2 4 9 - 8 3 7 )}$ \\
\hline Ultrafiltration $(\mathrm{ml} / \mathrm{h})$ & 128 \\
\hline ICU stay $($ days $)$ & 16 \\
\hline Length of Hospital Stay (days) & 37 \\
\hline 30-days Mortality $(\mathrm{N} ; \%)$ & $6 ; 40 \%$ \\
\hline
\end{tabular}

Table :2 Postoperative characteristics

The observation that EO is not removed by RRT is in agreement with our previous data in dialysis patients [36]. Plasma levels of EO were largely unaffected by treatment modality (haemodialysis and chronic ambulatory peritoneal dialysis) as well as by haemodialysis procedure.

\section{Conclusion}

EO may be considered a stress hormone that changes rapidly during acute volume expansion and blood pressure fall during CPB. Future studies will determine whether the use of EO as preoperative marker that will predict the incidence of postoperative AKI in cardiac surgery patients.

\section{Acknowledgements}

The authors acknowledge the expert technical assistance of Cinzia Scotti.

This study was supported in part by Italian Ministry of Health RFFSR-2008-1141719 (PM) and Italian Ministry of University and Scientific Research 2008W5AZEC_001 (PM).

\section{References}

1. Lameire N, van Biesen W, Vanholde R (2005) Acute renal failure Lancet 365 417-430.

2. Mariscalco G, Lorusso R, Dominici C, Renzulli A, Sala A (2011) Acute kidney injury: a relevant complication after cardiac surgery. Ann Thorac Surg 92: 15391547.

3. Mehta RL, Pascual MT, Soroko S, Savage BR, Himmelfarb J, et al. (2004) Spectrum of acute renal failure in the intensive care unit: the PICARD experience. Kidney Int 66: 1613-1621.

4. Bove T, Calabro MG, Landoni G, Aletti G, Marino G, et al. (2004) The incidence and risk of acute renal failure after cardiac surgery. J Cardiothorac Vasc Anesth 18: $442-445$.

5. Chertow GM, Burdick E, Honour M, Bonventre JV, Bates DW (2005) Acute kidney injury, mortality, length of stay, and costs in hospitalized patients. J Am Soc Nephrol 16: 3365-3370.

6. Bellomo R (2005) Defining, quantifying, and classifying acute renal failure. Crit Care Clin 21: 223-237.

7. Schoner W, Scheiner-Bobis G (2007) Endogenous and exogenous cardiac glycosides and their mechanisms of action. Am J Cardiovasc Drugs 7: 173-189.

8. el-Masri MA, Clark BJ, Qazzaz HM, Valdes R (2002) Human adrenal cells in 
Citation: Bignami E, Casamassima N, Frati E, Messaggio E, Corno L, et al. (2011) Endogenous Ouabain Changes Rapidly During Cardiac Pulmonary by Pass. J Steroids Hormon Sci S3:002. doi:10.4172/2157-7536.S3-002

culture produce both ouabain-like and dihydroouabain-like factors. Clin Chem 48: $1720-1730$

9. Schneider R, Wray V, Nimtz M, Lehmann WD, Kirch U, et al. (1998) Bovine adrenals contain, in addition to ouabain, a second inhibitor of the sodium pump. J Biol Chem 273: 784-792.

10. Zhang J, Hamlyn JM, Karashima E, Raina H, Mauban JR, et al. (2009) Low-dose ouabain constricts small arteries from ouabain-hypertensive rats: implications for sustained elevation of vascular resistance. Am J Physiol Heart Circ Physiol 297: 1140-1150.

11. Kimura K, Manunta P, Hamilton BP, Hamlyn JM (2000) Different effects of in vivo ouabain and digoxin on renal artery function and blood pressure in the rat. Hypertens Res 23: 67-76.

12. Kuznetsova T, Manunta $P$, Casamassima N, Messaggio E, Jin $Y$, et al. (2009) Left ventricular geometry and endogenous ouabain in a Flemish population. J Hypertens 27: 1884-1891.

13. Manunta P, Stella P, Rivera R, Ciurlino D, Cusi D, et al. (1999) Left ventricular mass, stroke volume, and ouabain-like factor in essential hypertension. Hypertension 34: 450-456.

14. Manunta P, Hamlyn J, Simonini M, Messaggio E, Lanzani C, et al. (2011) Endogenous ouabain and the renin angiotensin aldosterone system: distinct effects on $\mathrm{Na}$ handling and blood pressure in human hypertension. J Hypertens 29: 349-356.

15. Roques F, Nashef SA, Michel P, Gauducheau E, de Vincentiis C, et al. (1999) Risk factors and outcome in European cardiac surgery: analysis of the EuroSCORE multinational database of 19030 patients. Eur J Cardiothorac Surg 15: 816-822.

16. Colangelo N, Benussi S, Nascimbene S, Calvi S, Caldarola A, et al. (2003) Cardiopulmonary bypass strategy during concomitant surgical treatment of mitral valve disease and atrial fibrillation. Perfusion 18: 19-24.

17. Bellomo R, Ronco C, Kellum JA, Mehta RL, Palevsky P (2004) Acute rena failure - definition, outcome measures, animal models, fluid therapy and information technology needs: the Second International Consensus Conference of the Acute Dialysis Quality Initiative (ADQI) Group. Crit Care 8: 204-212.

18. Kumar AB, Suneja M (2011) Cardiopulmonary bypass-associated acute kidney injury. Anesthesiology 114: 964-970.

19. Blaustein MP, Zhang J, Chen L, Hamilton BP (2006) How does salt retention raise blood pressure? Am J Physiol Regul Integr Comp Physiol 290: 514-523.

20. Hamlyn JM, Manunta P (2011) Endogenous ouabain: a link between sodium intake and hypertension. Curr Hypertens Rep 13: 14-20.

21. Rossi G, Manunta P, Hamlyn JM, Pavan E, De Toni R, et al. (1995) Immunoreactive endogenous ouabain in primary aldosteronism and essential hypertension: relationship with plasma renin, aldosterone and blood pressure levels. J Hypertens 13: 1181-1191.
22. Manunta P, Ferrandi M, Bianchi G, Hamlyn JM (2009) Endogenous ouabain in cardiovascular function and disease. J Hypertens 27: 9-18.

23. Boulanger BR, Lilly MP, Hamlyn JM, Laredo J, Shurtleff D, et al. (1993) Ouabain is secreted by the adrenal gland in awake dogs. Am J Physiol 264: 413-419.

24. Manunta P, Hamilton BP, Gann D, Resau J, Hamlyn JM (1992) A new syndrome with elevated plasma ouabain and hypertension secondary to an adrenocortical tumor. J Hypertens 10: 27.

25. Masugi F, Ogihara T, Hasegawa T, Sakaguchi K, Kumahara Y (1988) Normalization of high plasma level of ouabain-like immunoreactivity in primary aldosteronism after removal of adenoma. J Hum Hypertens 2: 17-20.

26. Laredo J, Hamilton BP, Hamlyn JM (1994) Ouabain is secreted by bovine adrenocortical cells. Endocrinology 135: 794-797.

27. Wang JG, Staessen JA, Messaggio E, Nawrot T, Fagard R, et al. (2003) Salt endogenous ouabain and blood pressure interactions in the general population. J Hypertens 21: 1475-1481.

28. Sophocleous A, Elmatzoglou I, Souvatzoglou A (2003) Circulating endogenous digitalis-like factor(s) (EDLF) in man is derived from the adrenals and its secretion is ACTH-dependent. J Endocrinol Invest 26: 668-674.

29. Perrin A, Brasmes B, Chambaz EM, Defaye G (1997) Bovine adrenocortical cells in culture synthesize an ouabain-like compound. Mol Cell Endocrinol 126 7-15.

30. Lichtstein D, Steinitz M, Gati I, Samuelov S, Deutsch J, et al. (1998) Biosynthesis of digitalis-like compounds in rat adrenal cells: hydroxycholesterol as possible precursor. Life Sci 62: 2109-2126.

31. Mikkaichi T, Suzuki T, Onogawa T, Tanemoto M, Mizutamari H, et al. (2004) Isolation and characterization of a digoxin transporter and its rat homologue expressed in the kidney. Proc Natl Acad Sci U S A 101: 3569-3574.

32. Inui KI, Masuda S, Saito H (2000) Cellular and molecular aspects of drug transport in the kidney. Kidney Int 58: 944-958.

33. Tripodi G, Citterio L, Kouznetsova T, Lanzani C, Florio M, et al. (2009) Steroid biosynthesis and renal excretion in human essential hypertension: association with blood pressure and endogenous ouabain. Am J Hypertens 22: 357-363.

34. Bauer N, Muller-Ehmsen J, Kramer U, Hambarchian N, Zobel C, et al. (2005) Ouabain-like compound changes rapidly on physical exercise in humans and dogs: effects of beta-blockade and angiotensin-converting enzyme inhibition Hypertension 45: 1024-1028.

35. Huang BS, Ahmadi S, Ahmad M, White RA, Leenen FH (2010) Centra neuronal activation and pressor responses induced by circulating ANG II: role of the brain aldosterone-"ouabain" pathway. Am J Physiol Heart Circ Physio 299: 422-430.

36. Stella P, Manunta P, Mallamaci F, Melandri M, Spotti D, et al. (2008) Endogenous ouabain and cardiomyopathy in dialysis patients. J Intern Med 263: $274-280$.
This article was originally published in a special issue, Cellular Mechanism of Steroids handled by Editor(s). Dr. Tomoshige Kino, National Institutes of Health, USA 